\title{
E्己̌ruAão \\ Quando o Mundo Some: reflexões sobre o futuro da(s) leitura(s)
}

Claudemir Belintane'

'Universidade de São Paulo (USP), São Paulo/SP - Brasil

RESUMO - Quando o Mundo Some: reflexões sobre o futuro da(s) leitura(s). A partir de comparações entre diferentes suportes de expressão e de leitura, propõe-se uma reflexão sobre modos de ler e conhecer. Tomando como eixo reflexivo estudos sobre leitura e modos de enredamento subjetivo de diversos tempos cotejando-os com alguns autores e escritores modernos e contemporâneos, tematiza-se a fronteira entre mundo sensível e representação, com o objetivo de contribuir para uma crítica da apropriação de recursos midiáticos na educação. $\mathrm{O}$ argumento principal se estrutura a partir da premissa de que, diante do recobrimento da realidade pelas mídias contemporâneas, mais do que nunca cabe à educação preservar as possibilidades de aprender e de se apreender a partir dos incômodos do real. Palavras-chave: Letramento. Mídias. Leituras. Alfabeto.

ABSTRACT - When The World Disappears: reflections on the future of reading(s). This paper proposes a reflection on the different ways of reading and knowing based on comparisons between different means of expression and reading. Taking studies on reading as well as modes of subjective entanglement of different times and contrasting them to some modern and contemporary scholars and writers, the paper focuses on discussing the boundary between the sensible world and its representation, in order to contribute to a more critical appropriation of media resources by the educational system. The main argument poses itself from the premise that, in face of the concealment of reality by contemporary media, it is more than ever the task of education to preserve the possibilities to learn and to grasp from the discomforts of the real.

Keywords: Literacy. Media. Readings. Alphabet.

Educação \& Realidade, Porto Alegre, v. 43, n. 1, p. 275-291, jan./mar. 2018. 275 http://dx.doi.org/10.1590/2175-623664333 


\title{
Introdução
}

No filme Matrix (1999), dos irmãos Wachowski, Cypher, diante da grande mãe eletrônica com suas matrizes de zeros e uns, diz a Neo que, quando olha para aquelas insípidas colunas binárias, o que vê são imagens de mulheres, de cidades, imagens da vida. Para aguçar um pouco a abordagem do tema deste artigo, que contrapõe o mundo virtual do alfabeto ao do eletrônico, apresenta-se o fragmento abaixo, escrito por Apollinaire (1997, p. 61) no início do século XX, na velha tecnologia do alfabeto:

\begin{abstract}
Ela mantinha as coxas fechadas, mas logo meu dedo encontrou seu clitóris. Suas coxas se abriram sob a pressão de minha mão. Finalmente consegui enfiar meu indicador na xoxota úmida, mas não muito fundo, pois ela já se contraía. Pressionei seu hímen, em cujo centro já havia um pequeno orifício. Berta deu um gritinho de dor e contraiu-se mais.

Muito excitado, eu me despi, levantei a camisa e me pus em cima de minha irmã para penetrar em sua xoxota com meu membro cada vez mais duro. Berta protestou em voz baixa, começou a chorar e deu um gritinho quando entrei bem em sua vagina. Estava com as faces afogueadas, os belos olhos brilhantes, a boca entreaberta. Envolveu-me com os braços e correspondeu intensamente a meus embates.
\end{abstract}

É provável que muitos leitores se excitem com as imagens desse texto e muitos nem se choquem com o incesto diante dos olhos. Como diz Barthes, o leitor, no momento em que experimenta o seu prazer, é pura permissividade, suporta todas as contradições possíveis, "seria, pois, a abjeção de nossa sociedade” (Barthes, 1983, p. 36). Também podemos evocar Drummond de Andrade indagando a perda do mundo: "Como pode o homem/sentir-se a si mesmo/quando o mundo some?" (Andrade, 1967, p. 302) ou ainda Sócrates, nas palavras de Platão (2003, p. 120), dizendo que o texto escrito não responde diretamente às questões que o interlocutor lhe põe, apenas repete o mesmo texto, ou seja, não é capaz de uma interlocução viva, uma maiêutica, pois não traz um verdadeiro interlocutor presencial.

De certa forma, não há muitas diferenças entre as colunas verticais de zeros e uns da Matrix e as letras eróticas horizontais que Apollinaire nos apresenta, sobretudo se levarmos em conta que ambos são modos de ler e que, nos dois processos, transformam-se caracteres em imagens. Se conseguíssemos de fato transcodificar direta e rapidamente a codificação binária, como faz o personagem do filme, talvez pudéssemos dispensar definitivamente o alfabeto como sistema de representação que tem a linearidade da língua como referente. No entanto, o mundo binário, fora da fantasia do cinema, só se torna visível ou audível com a ajuda de uma interface amigável, uma janela (Windows) na qual predominam imagens, sons, letras e outras possibilidades gráficas não necessariamente lineares. Se para o texto de Apollinaire, as imagens 
em movimento resultam de uma identificação integrativa e retroativa de letras, sílabas, palavras, frases e períodos, mais precisamente de um pareamento com a linearidade da língua, na tela da máquina que transcodifica código binário, a leitura pode revelar imagens e sons diretamente, dispensando o leitor de um percurso intermediário, ou seja, não precisamos fazer o que os softwares fazem - em outras palavras, podemos dizer que esses meios teriam uma pregnância mais direta, pois são capazes de envolver nossos sentidos como se estivessem voltados diretamente para o colorido do mundo. Diante desses modos de enredamento do homem, neste contexto de sobreposição de tecnologias de representação, as questões levantadas por Barthes, Drummond de Andrade e Sócrates/Platão continuam sendo pertinentes? O leitor seja na tela do computador a um palmo do nariz ou imerso na realidade virtual, seja nas páginas de um livro ou na atmosfera de um contador de história, não é esse mesmo sujeito submetido (impregnado), que se deixa levar por uma parafernália sinestésica e fantasiosa? Uma das vantagens da leitura alfabética não estaria justamente nessa capacidade de escapar da pregnância que o meio oferece, como diz Barthes, levantando a cabeça? Exatamente por não ser contínua, seus hiatos associativos podem permitir certos estranhamentos e daí a possibilidade de tirar os olhos e sair da janela quando excessivamente atrativa.

Partindo dessas indagações, o objetivo deste ensaio é apresentar uma reflexão sobre os atos de ler e de aprender no contexto das tecnologias contemporâneas, tomando como referência alguns estudos sobre memória, suportes e modos de enredamento subjetivo de diversos tempos. Pretende-se, assim, revisitar essa subjetividade que se deixa "pegar totalmente" e cotejá-la a outra que de vez em quando consegue "levantar a cabeça" no ápice de seu gozo ou que se predispõe a fazer ressoar, nos intervalos de suas leituras e navegações, alguma paráfrase da dúvida de Drummond: o que sou ou quem sou eu, quando o mundo some? Como os suportes eletrônicos atuais são de uma pregnância mais imediata que a escrita, ou seja, oferecem um mundo sedutor e em movimento, disposto a ser manipulado, resta-nos indagar quais são as vantagens e desvantagens dessas características para a educação, para o ensino. Pretendemos conduzir essa reflexão sempre a partir da comparação entre os modos de enredamento e a pregnância de cada suporte e, em razão do ufanismo tecnológico que, a partir do mercado, assola as escolas públicas e privadas com novos produtos educacionais (mobile learning, ambientes virtuais, tabletes, etc.), colocaremos em jogo mais as desvantagens do que as vantagens.

\section{Janela das Almas: Quando o Mundo Some}

Fazer o outro ver cenas que não estão presentes ou então convencer alguém (ou ser convencido) sobre um acontecimento que já se esvaiu no pó do tempo são características humanas que implicam uma mediação, uma linguagem e algum tipo de suporte. O psiquismo humano é, por natureza, associativo, como diz Freud, é delirante. Desde o 
berço, o bebê é capaz de fazer repetir uma cena prazerosa em sua nascente memória e a ela se apegar como se essa imagem fosse a real - um exemplo é o bebê que assume prazerosamente uma teta imaginada e obtém com isso o seu prazer, chegando mesmo a rejeitar a teta viva que a mãe lhe oferece (Freud, 1988a, p. 228-239).

Ainda que a captação desse momento freudiano seja mítica, com poucas chances de comprovação científica, fica-nos uma certeza: somos dotados de alguma base psíquica que nos permite trocar a realidade por alguma coisa que nunca existiu ou que já não existe mais. Se Drummond de Andrade pergunta pela essência desse homem quando seus sentidos estão cravados fora do mundo, também entrevê, em A máquina do mundo, o mal-estar a que se pode estar sujeito quando a carnadura concreta do mundo se entremostra nas falhas de seu habitual recobrimento linguageiro:

\begin{abstract}
A máquina do mundo se entreabriu para quem de a romper já se esquivava e só de o ter pensado se carpia.
\end{abstract}

Abriu-se majestosa e circunspecta, sem emitir um som que fosse impuro nem um clarão mais que o tolerável.

pelas pupilas gastas na inspeção contínua e dolorosa do deserto, e pela mente exausta de mentar

toda uma realidade que transcende a própria imagem sua debuxada no rosto do mistério, nos abismos [...]

baixei os olhos, incuriosos, lasso, desdenhando colher a coisa oferta que se abria gratuita a meu engenho.

A treva mais estrita já pousara sobre a estrada de Minas, pedregosa, e a máquina do mundo, repelida,

se foi miudamente recompondo, enquanto eu, avaliando o que perdera, seguia vagaroso, de mãos pensas (Andrade, 1967, p. 271-273).

Para boa parte das ciências contemporâneas, a essência do homem está mesmo nesse pendor para a simulação, pois é a partir dela que erguem seus edifícios simbólicos, constroem seus mitos, literaturas, teorias e tecnologias. Talvez, a operação mais difícil e complexa a ser extraída desse dom seja a capacidade de retroagir sobre o efeito da ilusão para segurar minimamente alguns princípios que permitam cotejos com a ordem lógica ou (i)mediata do mundo. O poeta aqui reconhece a retração melancólica de nossos momentos de onipotência, corte este que, possivelmente, algumas ciências e intelectuais das tecnologias de hoje sequer o pressentiriam. 
Um dos grandes problemas filosóficos, diz Foucault (1996), é a verdade do mundo. Não é por acaso a emergência no Ocidente de uma maquinaria da verdade. Essa vontade de verdade do homem que, segundo o filósofo francês, é uma construção histórica relativamente recente, nasce com os gregos pós-homéricos, com a busca de uma alética, em que se precisava assegurar as condições lógicas básicas para que fosse possível deduzir quando uma sentença poderia ser declarada verdadeira ou falsa (entre elas, relembremos aqui o famoso princípio do terceiro excluído: uma coisa é ou não é, não vale a terceira hipótese, segundo a qual a coisa seria e não seria ao mesmo tempo) e avança até nosso dias, mas deambula um pouco quando voltamos a perguntar se de fato, diante da maquinaria simbólica e imaginária que nos envolve, o real consiste.

Freud (1988b), em um de seus primeiros textos, Projeto para uma psicologia científica (1895), já nota que o aparelho psíquico funciona por retroação, ou seja, o que se constata diretamente dos sentidos sobre o mundo é reeditado por memórias mais antigas. Tal qual a alucinação do bebê, nosso psiquismo poderia alucinar constantemente sobre a realidade não fosse um dispositivo que, segundo Freud, está ali postado de permeio para discernir entre o que de fato vem do mundo e o que se alucina (Freud, 1988b, p. 377) ${ }^{1}$. Talvez não seja por acaso a generalização da fantasia no mundo contemporâneo, que toda pessoa sinta um prazerzinho incomum ao se deixar enganar, e que se tenha emergido na história do homem uma parafernália discursiva e tecnológica para alimentar essas fantasias e perpetuar as impressões de realidade e, em contrapartida, uma outra sempre disposta a cortar os excessos de fantasiação e afirmar discursos sobre leis, objetividades e cientificidades.

Sabemos (nos dois sentidos) bem desse prazer quando vivemos, na literatura, no cinema ou na simples escuta de uma história, a possibilidade de aceitar a ficção como realidade. No escurinho do cinema ou imerso nas páginas de um romance ou ainda sendo conduzido pela voz de um contador-encantador, o psiquismo se deixa levar docilmente, constitui até uma corporalidade fantasiosa (um avatar?) para que o assujeitado viva as emoções do outro. Se o herói está prestes a cair do beiral de um prédio, compartilhamos suas emoções a ponto de nosso corpo suar frio, arrepiar-se, fazer gestos bruscos de defesa - é o que os antigos e modernos dramaturgos, seguindo Aristóteles, chamam catarse.

Entre os gregos, essa vocação para a catarse era aproveitada no ensino - havia uma pedagogia da catarse. Segundo Havelock (1996), o aedo, o rapsodo, não era um poeta tal qual os que conhecemos hoje, era antes um pedagogo, com suas epopeias na ponta da língua para ensinar o efebo, por exemplo, a compreender a força e o significado da cólera de Aquiles ou as astúcias de Ulisses. O aluno também memorizava os trechos significativos da epopeia e, por meio de uma vigorosa teatralização, incorporava os sentidos da cólera, da astúcia e de outros para, assim, por simulação, formar-se guerreiro e cidadão. O sistema despertou a crítica de Platão (2001), que em sua obra maior, A república, apregoou 
o fim desse tipo de ensino e a eficiência mais direta dos diálogos filosóficos, que buscavam mais o conceito do que a imagem alegórica.

Esse sistema de ensino grego só exigia um tipo de tecnologia: a poesia. Essa invenção das filhas de Mnemosine, as Musas, consistia em uma técnica de formulações orais (métrica, ritmo, repetições e outros recursos mnemônicos de origem oral), uma estética especial para ajudar a manter os grandes feitos na memória coletiva. Nos tempos homéricos, o poeta era, então, uma espécie de memorialista e pedagogo da sociedade grega, que emprestava seu corpo como suporte de perpetuação e vetor de transmissão dos feitos heroicos.

Já nos tempos de Platão, outra tecnologia ameaça a estética oral do Aedo e de outros mestres da oralidade (como Sócrates): a escrita. Como diz Havelock (1996), chegou um tempo em que a Musa aprendeu a escrever. Os versos e as imagens que foram matriciados na tecnologia oral deixaram o suporte úmido, mole e quente do psiquismo (hoje chamado wetwere) para se grafar na superfície seca e fria do pergaminho e do papiro. O efebo, em vez de ter diante de si o corpo pantomímico do aedo, passa agora a envesgar seus olhos num anteparo de mundo chamado livro. Bem mais tarde, quando Camões brande sua lira para cantar os feitos portugueses no mar tenebroso, dirige-se a uma musa que já sabia ler e que já portava, debaixo dos braços, um grosso volume de um tratado de estética no qual o canto dos heróis figurava com um modelo bem fixado pela escrita.

Já que vivemos um tempo em que a palavra janela é a metáfora articuladora dos ambientes virtuais (Windows XP, Milenium etc.), tomemos esse fenômeno como um conceito e vamos retroagir a partir dele: o que o rapsodo fazia com sua voz e sua pantomima diante do efebo não era também uma forma de cavar uma janela de evasão? A partir do ritmo e das imagens alegóricas que ressoavam em seus tímpanos e nervos, o jovem aluno deixava o prosaico mundo grego dos tempos de paz e ingressava virilmente nas batalhas sangrentas contra a urbe de Priamo (Troia). Mais tarde, com a dinamização do alfabeto e a invenção do livro, a janela podia ser aberta mesmo na solidão. Aliás, a leitura solitária foi sempre considerada uma heresia e só começa a ser notada e praticada a partir do século IV, veja-se, por exemplo, Santo Agostinho admirando a leitura de boca fechada de Santo Ambrósio, como algo incomum: "Mas, quando lia, os olhos divagavam pelas páginas e o coração penetrava-lhes o sentido enquanto a voz e a língua descansavam. Nas muitas vezes em que me achei presente [...] sempre o via ler em silêncio e nunca de outro modo" (Agostinho, 1984 p. 91). Ambrósio abria a sua janela de alienação e, através dela, saía da fria realidade de seu claustro.

Nos dias de hoje, as coisas mudaram: graças à janela cantante e deslumbrante dos computadores, passou a ser possível a um adolescente que ainda lê de boca aberta (silabando, subvocalizando sem arrepanhar sentido algum) engajar-se em jogos de luta (por exemplo, o Counter Strike) a ponto de perder o mundo lá fora. No verão de 2014, pude observar, no litoral paulista, as lan houses tomadas por crianças de periferia (durante a semana, sem turistas por lá, o preço da hora caia 
para um ou dois reais), que se apinhavam sobre os computadores, desprezando o mundo lá fora com suas belas praias ensolaradas com pipas rabeando no azul do céu.

Para a educação, para o ensino de linguagem, é interessante buscar o sentido ou os efeitos significantes dessa estranha curva no tempo! Estaria a Musa preferindo os rumorejos e explosões do jogo corporal dentro da tela à mediação que as letras vêm propondo ao longo dos milênios? Reunindo a diversidade possível de janelas, como podemos pensar o homem contemporâneo, que tão facilmente perde o mundo e ganha o outro das janelas eletrônicas de nossos dias? O filme Matrix, já sobejamente discutido por muitos intelectuais contemporâneos, trouxe a questão de uma forma popular e dicotômica, fazendo ressoar a saudação emblemática do imaginário de nosso tempo: Bem-vindos ao deserto do real. Essa expressão deu o título à coletânea de artigos de Zizek (2003) e subtítulo à coletânea de artigos organizadas por Irwin (2003). $\mathrm{O}$ conceito de real que se contrapõe à realidade virtual oscila bastante entre os diversos autores da segunda coletânea, o que tomamos como referência aqui está mais próximo do utilizado por Zizek (que também tem um artigo na coletânea de Irwin) ${ }^{2}$, que trata o real na acepção lacaniana, como aquele inexplicável que não se recobre pelos sentidos, conforme diz Lacan no Seminário - Livro 16 (p. 64), “[...] dizer que o real é impossível equivale também a enunciar que ele é apenas a apreensão mais extrema do dizer, na medida em que o dizer introduz o impossível e não simplesmente o enuncia”. Por meio de Zizek e Lacan, pretende-se aqui buscar esse cotejo entre o real e os sentidos, mas tentando escapar do visgo fácil do contraponto direto entre o real de realidade e o mundo virtual.

\section{Limites dos Sentidos}

Por mais pornográfico que possa parecer o texto de Apollinaire que abre esse artigo, não podemos qualificá-lo como tal, pois a câmera que nos leva para dentro da vagina, acompanhando o dedo e o pênis do narrador-protagonista, exige antes uma contraparte linguística, decodificação de palavras e frases. Se compararmos essas excitantes leituras dos livros proibidos dos séculos anteriores com a imensa disponibilidade de filmes pornôs nas janelas de hoje, podemos notar que este radical voyeurismo de nosso tempo convida os olhos a penetrar uma vagina ou um ânus até o limite da simples carne, em que nada mais se pode ver. Isso porque a configuração da imagem que temos na memória (como referência de mundo) atinge seu limite e se desfigura ao ocupar toda a extensão da janela, deixando entrever um real incompreensível para a linguagem do desejo - esta, apesar de mais-dizer a partir da parcialidade do objeto, faz isso se engajando a uma estética, a uma erótica, que está mais para o jogo do implícito do que para o escancaramento absoluto.

O que vai se tornando cada vez mais claro é que a tentativa de garantir o máximo da imagem direta do real, em seus instrumentos de 
mediação, por seu excesso de fidelidade ou seu excessivo poder de penetração, seja na pornografia, seja nas guerras e catástrofes filmadas em tempo real, acaba produzindo uma versão do próprio deserto do real (Zizek, 2003), que põe o sujeito a requerer sobre ele algum tapume simbólico ou imaginário.

Talvez seja por isso que um adolescente (de dezesseis ou quarenta anos) de nosso tempo, ao criar seu avatar em sua segunda vida, começa tentando esboçá-lo à sua imagem e semelhança, mas logo abandona os limites do projeto e alça voo em busca de uma imagem mais ao gosto de sua fantasia. Veja a receita dos próprios fabricantes de mundos:

Second Life Brasil, baseado em um game, é um jeito de expressar a sua 'segunda vida' aquela vida desejada, mas que agora você vai atingir. É como se você pegasse aquele avatar que você sempre imaginou - com alimentação regrada, exercícios diários e tudo mais - e tornasse realidade, de uma hora pra outra (Second..., 2016, online).

Possivelmente, é essa pré-fabricação da fantasia infantil que leva a criança a preferir combater heroicamente na lan house a participar da guerra de pipas na praia. O castelo de areia molhada da praia e uma possível batalha imaginária feitas com bonequinhos cedem vez às fortalezas que explodem diante de uma poderosa shot gun. A rapidez do esfacelamento da imagem (por exemplo, um homem explodindo ao ser alvejado) é compensada por outros aspectos sinestésicos (musiquinha rumorejante, pontos coloridos em profusão e bônus por mais vida) e pela substituição rápida deste ser por outro a ser alvejado, mas num nível de dificuldade maior, para que o desafio atinja seus infinitesimais pontos catárticos. A máquina, em suas possibilidades de demiurgia, parece ser bem propícia a experiências nas bordas da lei, onde se pode ser mais que um assassino dos tempos de Aquiles, pois ali na solidão da janela é que se pode experimentar o apagamento das cores e das imagens e ficar somente no disparo do clic mortal e na prontidão para um novo tempo de gozo como bônus. O bom jogador apaga o cenário no momento em que está diante da tela, fica apenas com o essencial, o não-pensar da destreza das mãos. Todo o fundo some para que a concentração fique apenas no disparo certeiro ou nos ágeis esquives.

Se compararmos estas atuais com as janelas do passado, constataremos que em outros tempos também se brincava com simulação: o poeta árcade com sua fazenda, suas ovelhas, seu cajado de mentira e sua Marília, que aceita deitar-se em um leito de feno, ou ainda a festa de Lord Byron quando se pode beber vinho em uma taça de crânio humano. Eis uma estrofe na tradução de Castro Alves:

Que este vaso, onde o espírito brilhava

Vá nos outros o espírito acender

Ai! Quando um crânio já não tem mais cérebro

Podeis de vinho o encher (Alves, 1958, p. 62).

Podemos também pensar no Quixote, viciado em livros de cavalarias, com seu Rocinante, lutando contra dragões-moinho e em busca 
de sua Dulcinéia. Outro exemplo seria Madame Bovary, de Flaubert, envolvida no clima romântico dos livros de sua época (exemplo: Paul et Virgine de Bernardin de Saint Pierre, publicado em 1787) em que seus heróis se sobrepunham sobejamente ao jeito prosaico e simples de seu marido, Charles Bovary.

Tanto os contornos macabros da poesia da geração egótica, como as pirações de Quixote e os devaneios de Madame Bovary ainda estão aí, enquanto temáticas de fantasiação a serem excitadas, propiciando evasões por meio das janelas do cinema, da TV (quantas Madames Bovarys as TVs têm cativas?) e, mais hodiernamente, por meio da Internet e dos jogos. Nas infinitas pontas do Facebook moram também heróis românticos e dulcineias de ambos os sexos para todas as falsas idades possíveis. Nos jogos de simulação, em que seu avatar sai quixotescamente em busca de aventuras, o envolvimento pode ganhar as sofisticações futurísticas da realidade virtual, que dispensariam janelas palpáveis no mundo externo e até mesmo um banco prévio de memórias, já que se vislumbram possibilidades de acionar as imagens de seu próprio estoque (talvez, como Quixote, Bovary ou qualquer outro leitor imaginoso do passado faziam a partir da leitura):

\begin{abstract}
Agora imagine um sistema que acessa suas memórias e vai substituindo paredes, chão, mesas, ambientes e personagens pré-definidos do jogo por tudo aquilo que você já tem armazenado no seu cérebro. Isso não é mais um jogo, isso virou um remake da sua vida. Você vai poder carregar o pacote de expansão 'férias em Plutão' e levar a família toda pra passear. Você vai poder dar um load em 'World of Warcraft XXX' e vai fazer sexo com ELFAS, cara! Não quero nem pensar nos novos fetiches e modalidades de sexo que vão aparecer (Gamehall, 2016, online).
\end{abstract}

Para se fazer um excitante sexo com Elfas, esse sistema wetware também teria que bloquear os impulsos elétricos que intumescem o pênis e excita a vesícula seminal, para que a ejaculação possa se dar apenas no mundo virtual e não no abandonado mundo do corpo real. Invertendo parodicamente o que diz Lacan no Seminário 20 (1985), podemos afirmar que esses remakes da vida só nos fazem pensar que a relação sexual não existe mesmo e que ela migra do plano parcial para a busca do gozo total.

O corpo como resíduo das fantasiações cibernéticas poderia até, não fosse o compromisso com o trabalho e outros, transformar-se em uma esfera como a tematizada pelo discurso de Aristófanes no Banquete de Platão (1999), mas agora sem o perigo da descarga total sobre o corpo (gozo mortal) durante a relação sexual, já que o sistema wetware poderia garantir um gozo parcial apenas na virtualidade dos Elfos, deuses e demônios. Entretanto, já que é possível se aproximar das divindades e até fazer sexo com elas, entrevemos aí também a possibilidade do gozo total, gozo de Santa Tereza (Lacan, 1985).

Até aqui estamos vendo que o psiquismo humano parece ser o grande responsável por tudo, já que é mais propenso à fantasiação do 
que à realização. Mas saberíamos nós localizar diferenças quando os meios de expressão mudam abruptamente? Que diferenças há neste percurso que vai do efebo grego vivendo no corpo a cólera de Aquiles ou as manobras do astuto Ulisses ao internauta gozante de hoje (sem dispensar o futurístico wetwere com seus plugs na carne), passando pelos que se evadiam e ainda se evadem nos mundos que brota(v)am das páginas de livros? Como podemos pinçá-las e pensá-las?!

Pincemos algumas diferenças. No caso do Efebo da tradição homérica, o corpo está lá como primeira instância da fantasiação, a pantomima feita pelo rapsodo e mimetizada pelo jovem guerreiro domestica o plug-in freudiano do teste de realidade, pois o jovem guerreiro sabe que levará no corpo algo para enfrentar a vida. Nesse contexto, a encarnação (encadernação?) do texto, sob a catarse de Mnemosine, é o fundamento da técnica. A métrica, o ritmo, a estrofação, as alegorias e outros recursos estéticos constituem os elementos de uma tecnologia da encarnação do texto. Em seu Inconsciente Estético, Rancière, retomando Vico, mostra as radicais diferenças entre esse uso da palavra e os de nosso tempo, e afirma que Homero não era um criador de fábulas, de tipos e caracteres (Aquiles, Ulisses) ou mesmo um poeta com um singular domínio estético, mas sim alguém em sintonia com a linguagem de seu tempo:

Simplesmente vivia num tempo em que o pensamento não se separava da imagem, tampouco o abstrato do concreto. [...] Ele é apenas testemunha de um estado da linguagem em que a palavra era idêntica ao canto. Os homens, com efeito, cantaram antes de falar (Rancière, 2009, p. 29).

Esse cantar, é bom reafirmar, é de corpo presente, é ritualístico. Sua aprendizagem se dá - como ocorre também com nossos cantadores nordestinos - pelo envolvimento catártico, pelo transe obtido graças à invocação das Musas. Nossos repentistas, não raro, também pedem inspiração a Deus, à Nossa Senhora, fecham os olhos para evocar a memória cantadora e mudam a voz, buscando uma nasalização quase mântrica. Alguns cantadores chegam a dizer que o instrumento, a viola, não precisa ser afinado, que o importante é sua estridência e seu som rachado, mais próximo da voz nasal desafinada do que daquela do cantor que se esmera em executar uma pauta melódica. Com isso reafirmam a posição de poetas cantadores e não de cantores, em outras palavras, que são descendentes de Homero e não das escolas europeias de música.

Com a academia de Sócrates e Platão, a presença corporal dos interlocutores no ato da aprendizagem continua sendo fundamental, mas a inspiração e o comprometimento do corpo (mímese, pantomima) cederão lugar a uma certa ascese conceitual. A maiêutica pedia uma atenção reflexiva, outra postura em que o diálogo devolvia ao aprendiz uma pergunta sobre a sua própria afirmação. O corpo presente do filósofo continua importante, pois este, ao contrário do livro, está lá presente, vivo, predisposto a interagir. A retenção e retransmissão do evento filosófico também se efetivavam, como se pode ver no início do Banquete, 
em que Apolodoro diz a Glauco que está preparado para retomar o discurso dos convivas, ocorrido há muitos anos, quando ainda era criança, e que o ouvira da boca de Aristodemo, que estivera presente no evento. Essas retransmissões de Aristodemo a Apolodoro, depois a Glauco no início do Banquete, apesar de ter por trás a figura de Platão como autor do texto, mostram os cuidados do narrador com a fidelidade ao texto original, com sua reedição cotejada.

Nessas duas pinçadas, já podemos ver que, mesmo na técnica filosófica platoniana, algo do mundo homérico permanece ainda que como recurso estético da escrita nascente: a memória, a gravação fiel das palavras (ainda que a encenação corporal fique de fora) continuam importante, sobretudo no momento do ensino, da retransmissão, que a escrita do filósofo, em sua busca de verossimilhança, faz questão de reatualizar.

Com o advento da escrita, as obras dispensaram o corpo como único suporte, mas continuaram requerendo uma memória leitora e até mesmo um leitor de texto em voz alta, que perdurará por muito tempo, como ainda vemos no texto de Santo Agostinho citado páginas atrás. Segundo Cavalo e Chartier (1998) e Saenger (1998) a leitura em voz alta vai se manter até o século XII, quando se consolidaram as mudanças necessárias (espaços intervocabulares, marcas de pontuação) para que o livro se adequasse mais à leitura inspiciere, à leitura silenciosa e concentrada. A partir dessas sofisticações editorais, o copista preparava o texto para o leitor. Se antes, diante da scripta continua, o leitor tinha que entonar a voz para descobrir as unidades lexicais, frasais e seus sentidos no texto, a partir desse momento, o monge copista faz esse trabalho de facilitação da leitura por ele. De lá para cá, é interessante indagar quais facilitações, leitor e escritor vieram encontrando. Em nosso tempo, o hipertexto é um desses recursos autorais que investe na desconfiança em relação a uma possível memória intertextual do leitor, adiantando-lhe associações e, ao mesmo tempo, relegando-o à categoria de leitor que precisa de ajuda.

Para Cavalo e Chartier (1998, p. 27), a tão celebrada invenção da imprensa não produziu mudanças radicais nos modos de ler como o fizeram a passagem do rolo para o códice e a criação dos espaços intervocabulares, que vão fundar a possibilidade de ler em silêncio, de transformar o livro em obra verdadeiramente intelectual. A invenção de Gutemberg contribuiu enormemente para a expansão do público leitor, já que ampliou desmedidamente a circulação do livro. Se compararmos essa expansão com o milagre do e-reader (suporte eletrônico de texto ou livro eletrônico), talvez também possamos notar que não haverá mudanças significativas nos modos de ler se levarmos em conta somente a portabilidade da biblioteca pessoal dentro da maquininha. Sem dúvida, hoje um leitor pode ir para rede ou cama com alguns milhares de obras (e-books) no seu $e$-reader ou tablet, mas o modo de ler em si pouco se altera nessa simples transposição de texto antigo para novo suporte, ainda que se tenha ali o hipertexto, espaços para anotações, recorte-cole e a possibilidade de se salvar tudo isso preservando integralmente 
o texto matriz, pois boa parte desse processo de facilitação o livro já trazia, e as pontuações do leitor também não são tão novas. As obras antigas dentro das máquinas novas ainda impõem ao leitor a dureza do esforço concentrado, a solidão, o silêncio e as asperezas do alfabeto e da textualização antiga (paragrafação, pontuação, períodos longos e bem subordinados, elipses, etc.) mesmo quando reeditadas com as facilidades do mundo eletrônico.

O que também se evidencia no mundo contemporâneo é a sucessão de aparelhos cada vez mais eficientes: o $e$-reader, por exemplo, já nasceu perdendo espaço para outros equipamentos mais sincréticos, como, por exemplo, o ipad, o tablete ou mesmo os celulares que, a touch de dedo, conseguem ser redes sociais, cinema, TV, jornal, livro, agenda, computador, etc. Na euforia dessas sucessões na educação, talvez o que se está paulatinamente pondo de lado seja o nosso leitor silencioso, herdeiro de Santo Ambrósio, que aprendera a se isolar dos outros e do mundo para o mergulho em sua janela manuscrita iluminada à vela. Os que ainda restam (nós), provavelmente, irão manter os seus livros rotos e sujos por muito tempo, longe talvez da geração $\mathrm{Y}^{3}$, que já vem sendo instigada a outros tipos de leituras, com muito mais editoração, pois os novos textos já estão vindo em boa parte lidos pela editoração/ programação. Em outras palavras, as gerações estão sendo convidadas a aprender por imersão em janelas cantantes e rumorejantes.

A partir dessas nossas comparações e dos incômodos típicos de geração X, convém indagar se este leitor novel não estará ainda mais suscetível a essa catarse, não ficará à mercê do mundo de imagens, de ícones e de janelas sem bordas. Claro que caberiam ainda outras indagações mais esperançosas: os sistemas do futuro preverão oportunidades de ele levantar a cabeça a exemplo do que nos sugere Barthes? Será que essa tão cantada e quase onipresente interatividade tanto com textos e programas em si, como com outros internautas (ou leitores?) e redes sociais conseguirá garantir por si uma abertura para autonomia, para algum pensamento crítico, alguma maiêutica? Conseguirão, ao dispensar o alfabeto, atingir os níveis de abstração que este atingiu?

De quais modelos de leitura o leitor do mundo eletrônico está mais próximo? Não seria do efebo diante das pantomimas de seu rapsodo? Não teria algo do leitor medieval que passivamente escutava leitura em voz alta, que do átrio governava a sua imaginação? Teria algo da leitura inspiciere? Para nós, além de ele já ter nascido Y, envolto pela tecnologia digital, é também herdeiro direto do leitor contemporâneo, com seus livros ilustrados e suas colunas de poucas letras, sobretudo os que nos últimos tempos têm feito a fortuna de seus editores (livros-brinquedos, livros de armar, de jogar, livros de colorir, edições animadas em suporte eletrônico, etc.) ao custo de relegar para o cantinho dos fundos das livrarias e das bibliotecas os autores mais caudalosos dos jovens de dantes, como Andersen, Swfit, Collodi, Barrie, Lobato e outros. Considerando nossa história recente, podemos afirmar que não é por acaso que boa parte dos professores e das crianças contemporâneas (mesmo os/ as que frequentam bibliotecas) acredita que a Pequena Sereia, Gulliver, 
Pinóquio, Peter Pan, Emília e outros heróis da tradição infantil sejam criações dos estúdios Disney ou da Rede Globo de Televisão, ou seja, que são heróis criados para serem vistos e não para serem lidos. $\mathrm{O}$ avanço na qualidade gráfica, as sucessivas adaptações de obras literárias para o cinema, para a TV e, atualmente, para o suporte eletrônico (versões interativas) vêm preparando um tipo de leitor que praticamente dispensará a milenar tecnologia do alfabeto e o velho códice com sua lombada exposta na biblioteca. A crença atual na ideia de que um meio coetâneo incentiva o anterior, em relação às artes que usam o alfabeto, encontra neste milênio os seus limites.

Há pensadores atuais que nada mais esperam do alfabeto. Um deles é Jaron Lanier, que, a exemplo da autora que sonha o sexo com os Elfos, antevê a revolução da realidade virtual no estilo Matrix. Um mundo em que se pode não apenas olhar para as coisas e interpretá-las, mas também agir sobre elas e com elas - um mundo Matrix! Para Lanier, a linguagem das palavras (sobretudo a da escrita) é

[...] limitada; não se pode fazer uso dela para agir diretamente sobre a realidade. É um riacho estreito na enorme planície da realidade [...] É um fluxo de pequenos símbolos descontínuos, quando o mundo é feito de continuidades. A linguagem não pode mais que sugerir; não pode reproduzir a realidade nem criá-la. Nenhuma pintura poderá jamais ser completamente descrita por palavras; muito menos o mundo (Lanier apud Lévy, 1998 p. 29).

Lévy, apesar de concordar apenas parcialmente com Lanier, também relaciona o alfabeto a antigas tecnologias e vê a possibilidade da emergência de uma nova escrita, a "ideografia dinâmica":

\begin{abstract}
Até o presente momento, os computadores têm sido para seus usuários o suporte eficaz de antigas tecnologias intelectuais (escritas, alfabéticas, grafismos diversos, signos matemáticos, imagens animadas etc.) acrescentando-lhes um toque de conforto e interatividade em tempo real. Em vez disso, a ideografia dinâmica funcionaria muito bem como nova tecnologia intelectual, pois, intrinsecamente relacionada à informática, se imbricaria diretamente com o sistema cognitivo de seus usuários (Lévy, 1998, p. 53).
\end{abstract}

Essa possível nova tecnologia informacional estaria mais próxima da escrita chinesa do que do alfabeto ocidental, que toma por modelo a dupla articulação da linguagem falada. Teria ainda essa ideografia virtual, segundo Lévy, a imensa vantagem de não estar presa a um suporte estático e a um sistema de memória limitado. Contaria com a possibilidade de articular diretamente os órgãos dos sentidos à própria significação, traduzindo diretamente "um modelo mental com a mediação da imagem e do movimento" (Lévy, 1998, p. 84). Acrescenta ainda que a ideografia dinâmica poderá ser a primeira escrita a adquirir um estatuto equivalente ao de uma língua, já que poderá contar com uma "imediatidade sensório-motora" (Lévy, 1998, p. 85). 
O alfabeto e seus antigos e modernos suportes, por mais que se tenha deles uma memória afetiva - não podemos negar -, são tecnologias inventadas pelo homem e, como tais, podem ser datadas, ter seu início, apogeu e fim. Haverá, com certeza, um (ou vários) sistema(s) de expressão e de interação por meio do(s) qual(is) se poderá expressar todo tipo de pensamento, desde os mais concretos aos mais abstratos, além de, como é o caso do alfabeto e do livro, servirem também como objetos de entretenimento e de convívio social. Muito provavelmente, nesses meios, teremos profissionalismos, intelectualismos, quixotismos e bovarismos, talvez de uma forma mais imbricada e pregnante do que a do livro. Se até as décadas finais do século XX, para enganar o professor, um estudante podia ocultar um romance de aventuras ou HQ no meio das páginas de um sisudo livro de estudos, hoje, na mesma posição, o que conta é a agilidade no comando alt tab (alternar) ou o tapinha rápido na tela (touch), que permite fugir aos olhos do professor que vem bisbilhotar se ele está estudando, apenas se divertindo ou fazendo sexo virtual com Elfos.

A leitura binária de Cypher ou os leitores de Apollinaire, muito provavelmente, também deixarão de existir - talvez os segundos ainda possam resistir por um bom tempo em comunidades clandestinas como as do Fahrenheit 451 de Bradbury (2009) - o título desta obra de 1953 baseia-se na temperatura de combustão do papel (451 graus fahrenheit). Seu herói, o bombeiro Montag, responsável pela incineração dos livros, que ainda resistiam ao predomínio do audiovisual (das salas com três ou quatro paredes que envolvem o espectador e com ele simula diálogos), vive uma grande aventura, pois ao assumir-se como leitor de livros terá que se refugiar na comunidade resistente, que dispensa o suporte de papel para preservar as grandes obras diretamente na memória, onde cada integrante é uma obra reencarnada.

Nas próximas décadas, o que deverá dominar mesmo é essa janela amigável, atrativa, de bordas invisíveis, com seus universos preparados para a imersão total seja na aventura ou no consumo (talvez esses dois universos percam de vez suas bordas). Que chances teria o mundo de “[...] se comer com os dentes, um mundo de volumosas dálias e tulipas" (Lispector, 1982, p. 24) que Clarice põe aos pés de Ana, no conto Amor, após ter seus olhos abertos pela visão inusitada de um cego mascando chiclete na escuridão? Ou aquele, de mesma essência, que A máquina do mundo de Drummond (como vimos atrás) desvela enquanto possibilidade de estranhamento entre corpo e linguagem?

Com a realidade virtual, a janela quase real de Lanier, onde os objetos podem ser tocados e transformados segundo nosso desejo (rei Midas?), um mundo que por si já é uma linguagem, manteria alguma borda para a desconfiança, mesmo que fosse, para o deserto do real, como o livro e as mídias de hoje ainda as mantém - por exemplo, aquelas pequenas levantadas de cabeça de Barthes? Nesse mundo-imagem, com poder de ação sobre objetos, poderia haver magrittes alertando que "isto não é um cachimbo", que em tela e tinta não é possível fumar ou o sujeito virtual fumaria prazerosamente como também faria seu sexo 
à vontade, sem o menor problema ético ou estético? E o neurótico contemporâneo com suas dores, encontraria uma maneira de manipular seus sonhos, seus objetos de tal forma a abrir a válvula mestra de seus desejos ou continuaria com a sua miséria pessoal tentando dar conta dos simulacros que nutrem suas fantasias? Se a análise for virtual, não será possível transar com o/a analista (que até pode ser um Ogro ou um Elfo) sem problemas éticos ou biomédicos? E o professor não poderia ser escolhido virtualmente e explodido tão logo dele o aluno se enfastiasse?

São perguntas difíceis de responder, mas, se estamos ainda sujeitos às leis físicas e psíquicas de um mundo carnudo - que nossa linguagem de fato só finge tocar -, se o mundo virtual ainda nos causa alguma indignação, se somos da geração X - que ainda quer insistir nas letras, no alfabeto e na crueza do mundo -, resta-nos uns velhos truques, que talvez até possamos ensinar à geração $\mathrm{Y}$ (mais afeita ao mergulho!): levantar a cabeça sempre, seja das páginas, das telas ou do envoltório sem bordas da realidade virtual; insistir nas dálias rechonchudas, na leveza das tulipas e nos sons de seus sapatos quando se palmilha alguma velha estrada de Minas, como nos ensinam os velhos escritores do quase ultrapassado alfabeto. Também seria importante defender uma velha coragem que nos isola(va) do sorvedouro das letras, esta coragem que Drummond, em Elegia 1938, assim expressou "A literatura estragou suas melhores horas de amor/Ao telefone perdeste muito, muitíssimo tempo de semear" (Andrade, 1967, p. 115). Outro truquezinho interessante seria um alt tab ou um touch real para a janela do quintal onde ainda se poderia preservar um cajueiro com frutas maduras, pedindo línguas e dentes.

Diante dos pretensiosos projetos da Google, de monitorar ou mesmo assumir boa parte dos serviços prestados pelo Estado em sua poderosa plataforma (educação, transportes, serviços médicos, etc.), talvez os passos mais revolucionários que os educadores possam dar neste milênio sejam no sentido de recuperar/preservar a capacidade de exercitar os sentidos - em suas bordas psicobiológicas - diante da máquina do mundo (Drummond) ou descobrir, com Ana no Jardim Botânico (Lispector, ainda o conto Amor), que desvelar a crueza do mundo é também enfrentar o medo do inferno. Nesse sentido, uma escola pode muito bem se posicionar como o lugar em que crianças e adolescentes se encontram com mundos perdidos (a natureza de se pegar com mão real, o conhecimento do passado, a filosofia, a literatura, as artes e as ciências que não se deram bem nas janelas digitais), já que, segundo apregoam os ufanistas das novas tecnologias, para os conhecimentos do futuro (novas artes, novas ciências), a aprendizagem, patrocinada pelos grandes provedores em rede, poderá se dar dentro de mundos virtuais, e cada indivíduo poderá ter sua gozante second life sem precisar despender esforços com abstrações e outras exigências dos antigos intelectuais. Resta aos educadores desconfiar e, enquanto desconfiam, levar seus alunos aos jardins botânicos para fotografarem com os olhos de ver. Quem sabe os sucessores desta geração - a geração Y2 - não levarão consigo a subversão que os incômodos do real ainda causam?

Educação \& Realidade, Porto Alegre, v. 43, n. 1, p. 275-291, jan./mar. 2018. 
Recebido em 26 de abril de 2016 Aprovado em 21 de fevereiro de 2017

\section{Notas}

1 Nesta mesma página, há uma nota de rodapé do Editor Inglês da Edição Stand, que diz ser essa a primeira tentativa de Freud tratar do "teste de realidade, de como decidimos se uma coisa é real ou não".

2 O artigo se intitula Matrix: ou, os dois lados da perversão (Irwin, 2003).

3 Diz-se das gerações que contaram desde a infância com as tecnologias digitais. Distinguem-se das gerações $X$, que não contaram com essa imersão tecnológica. Costuma-se dizer que as gerações $Y$ envolvem-se nos meios digitais de forma mais efetiva e completa, sem os vacilos, as desconfianças e até as reações que afetariam as gerações X.

\section{Referências}

AGOSTINHO, Santo. Confissões. Tradução de J. Oliveira Santos e A. Ambrosio de Pina. São Paulo: Abril Cultural, 1984. P. 5-288. (Coleção Os Pensadores).

ALVES, Castro. Espumas Flutuantes. In: ALVES, Castro. Poesias Completas de Castro Alves. Rio de Janeiro: Editora Tecnoprint, 1958. P. 62. (poema de Lord Byron, "Uma Taça Feita de Um Crânio Humano" traduzido por Castro Alves).

ANDRADE, Carlos Drummond de. Obra Completa. 2. ed. Rio de Janeiro: José Aguilar Editora, 1967.

APOLLINAIRE, Guillaume. As Façanhas de um Jovem Don Juan. Tradução de Monica Stahel. São Paulo: Editora Imaginário, 1997.

BARTHES, Roland. O Prazer do Texto. Tradução de Maria M. Barahona. Lisboa: Edições 70, 1983.

BRADBURY, Ray. Fahrenheit 451. Tradução de Cid Knipel. São Paulo: Globo, 2009. CAVALO, Guglielmo; CHARTIER, Roger. Introdução. In: CAVALO, Guglielmo; CHARTIER, Roger (Org.). História da Leitura no Mundo Ocidental. Tradução de Guacira M. Machado. São Paulo: Editora Ática, 1998. P. 5-40.

FOUCAULT, Michel. A Ordem do Discurso: aula inaugural no Collège de France, pronunciada em 2 de dezembro de 1970. Tradução de Laura F. de A. Sampaio. São Paulo: Edições Loyola, 1996.

FREUD, Sigmund. Formulações sobre os dois princípios do funcionamento mental. Tradução de José O. de Aguiar Abreu. In: FREUD, Sigmund. Edição Standard das Obras Completas de Sigmund Freud. v. XII. 2. ed. Rio de Janeiro: Imago, 1988a. P. 232-235.

FREUD, Sigmund. Projeto para uma psicologia científica [1950/1895]. In: FREUD, Sigmund. Edição Standard das Obras Completas de Sigmund Freud. v. I. 2. ed. Rio de Janeiro: Imago, 1988b. P. 333-443.

GAMEHALL. Videogames: os próximos 25 anos, 2028. Brasil: UOL, 2016. Disponível em: <http://gamehall.uol.com.br/site/video-games-os-proximos-25-anos-2028>. Acesso em: 04 abr. 2016.

HAVELOCK, Eric. A Musa Aprende a Escrever: reflexões sobre a oralidade e a literacia da antiguidade ao presente. Tradução de Maria Leonor Santa Bárbara. Lisboa: Gradiva, 1996.

290 Educação \& Realidade, Porto Alegre, v. 43, n. 1, p. 275-291, jan./mar. 2018. 
IRWIN, Willian. Matrix: ou, os dois lados da perversão. In: IRWIN, Willian (Org.). Matrix: bem-vindo ao deserto do real. Tradução de Marcos M. Leal. São Paulo: Madras, 2003. P. 259-279.

LACAN, Jacques. O Seminário 20: mais, ainda. Tradução de M. D. Magno. 2. ed. Rio de Janeiro: Jorge Zahar Editor, 1985.

LACAN, Jacques. O Seminário, livro 16: De um outro ao outro. Tradução Vera Ribeiro. Rio de Janeiro: Jorge Zahar Editor, 2008.

LÉVY, Pierre. A Ideografia Dinâmica: rumo a uma imaginação artificial? Tradução de Marcos Marcionilio e Saulo Krieger. 2. ed. São Paulo: Edições Loyola, 1998.

LISPECTOR, Clarice. Amor. In: LISPECTOR, Clarice. Laços de Família. 12. ed. Rio de Janeiro: José Olympio, 1982. P. 17-30.

MATRIX, The. Direção: Andy Wachowski e Lana Wachowski. Intérpretes: Keanu Reeves; Laurence Fishburne; Carrie-Anne Moss. EUA, 1999. 1 DVD (136 min.).

PLATÃO. A República. Tradução de Edson Bini. Bauru: Edipro, 2001.

PLATÃO. Fedro. Tradução de Alex Marins. São Paulo: Martin Claret, 2003.

PLATÃO. O Banquete ou Do Amor. Tradução de J. Cavalcante de Souza. Rio de Janeiro: Bertrand Brasil, 1999.

RANCIÈRE, Jacques. O Inconsciente Estético. Tradução de Monica Costa Neto. São Paulo: Editora 34, 2009.

SAENGER, Paul. A leitura nos séculos finais da idade média. Tradução de J. A. de Macedo Soares. In: CAVALO, Guglielmo; CHARTIER, Roger (Org.) História da Leitura no Mundo Ocidental. São Paulo: Editora Ática, 1998. P. 147-184.

SECOND Life Brasil. Avatar (descrição). Brasil, 2016. Disponível em: <http:// www.secondlifebrasil.com.br/?s=avatar $>$. Acesso em: 26 abr. 2016.

ZIZEK, Slavoj. Bem-Vindos ao Deserto do Real: cinco ensaios sobre o 11 de setembro e datas relacionadas. Tradução de Paulo Cesar Castanheira. São Paulo: Boitempo Editorial, 2003.

Claudemir Belintane é professor livre-docente da Faculdade de Educação da Universidade de São Paulo. Departamento de Didática e Metodologia de Ensino, Área de Linguagem.

E-mail: claubelintane@uol.com.br 